\title{
BMJ Open Association between low dietary zinc and hyperuricaemia in middle-aged and older males in China: a cross-sectional study
}

\author{
Dong-xing Xie, ${ }^{1}$ Yi-lin Xiong, ${ }^{1}$ Chao Zeng, ${ }^{1}$ Jie Wei, ${ }^{2}$ Tuo Yang, ${ }^{1} \mathrm{Hui} \mathrm{Li},{ }^{1}$ \\ Yi-lun Wang, ${ }^{1}$ Shu-guang Gao, ${ }^{1}$ Yu-sheng Li, ${ }^{1}$ Guang-hua Lei ${ }^{1}$
}

To cite: Xie D-xing, Xiong Ylin, Zeng C, et al. Association between low dietary zinc and hyperuricaemia in middleaged and older males in China: a cross-sectional study. BMJ Open 2015;5: e008637. doi:10.1136/ bmjopen-2015-008637

- Prepublication history for this paper is available online. To view these files please visit the journal online (http://dx.doi.org/10.1136/ bmjopen-2015-008637)

$\mathrm{D}-\mathrm{XX}$ and $\mathrm{Y}-\mathrm{IX}$ contributed equally.

Received 29 April 2015 Revised 13 August 2015 Accepted 20 August 2015

CrossMark

\begin{abstract}
${ }^{1}$ Department of Orthopaedics, Xiangya Hospital, Central South University, Changsha, Hunan Province, China

${ }^{2}$ Department of Epidemiology and Health Statistics, School of Public Health, Central South University, Changsha, Hunan Province, China
\end{abstract}

Correspondence to Dr Guang-hua Lei; Igh9640@sina.cn

\section{ABSTRACT}

Objective: To examine the associations between dietary zinc intake and hyperuricaemia.

Design: Cross-sectional study.

Setting: This study was conducted in a health examination centre of China.

Participants: A total of 5168 middle-aged and older participants (aged 40 years or above) (2697 men and 2471 women) were included.

Outcome measures: Dietary zinc intake was assessed using a validated semiquantitative food frequency questionnaire. Hyperuricaemia was defined as uric acid $\geq 416 \mu \mathrm{mol} / \mathrm{L}$ for males and $\geq 360 \mu \mathrm{mol} / \mathrm{L}$ for females.

Results: For males, the prevalence of hyperuricaemia was $22.9 \%$. After adjusting for age, body mass index (BMI) and energy intake, the ORs were 0.68 (95\% Cl 0.45 to 0.92$)$ in the second quintile, $0.63(95 \% \mathrm{Cl} 0.45$ to $0.89)$ in the third quintile, $0.68(95 \% \mathrm{Cl} 0.46$ to 1.00$)$ in the fourth quintile and $0.55(95 \% \mathrm{Cl} 0.35$ to 0.87$)$ in the fifth quintile comparing the lowest quintile of $\mathrm{Zn}$ intake, respectively ( $p$ for trend $=0.03$ ). In the multivariable adjusted model, the relative odds of hyperuricaemia were significantly decreased by 0.71 times in the second quintile of zinc intake (OR $0.71,95 \% \mathrm{Cl} 0.52$ to 0.98 ), 0.64 times in the third quintile (OR $0.65,95 \% \mathrm{Cl} 0.44$ to 0.94 ) and 0.55 times in the fifth quintile (OR 0.56, 95\% $\mathrm{Cl} 0.32$ to 0.97 ) compared with those in the lowest quintile, and $p$ for trend was 0.064 . For females, the prevalence of hyperuricaemia was $10.0 \%$, and unadjusted, minimally adjusted as well as multivariable adjusted ORs all suggested no significant association between dietary zinc intake and hyperuricaemia.

Conclusions: The findings of this cross-sectional study indicated that dietary zinc intake was inversely associated with hyperuricaemia in middle-aged and older males, but not in females. The association was significant after considering the influence of age, BMI and energy intake, and after that, minimum adjustment remained independent of further confounding factors such as vitamin C intake, alcohol drinking status and nutrient supplementation.

\section{INTRODUCTION}

Hyperuricaemia (HU) occurs when serum uric acid, the final product of purine

\section{Strengths and limitations of this study}

- This is the first study conducted on a large sample to explore the association between dietary zinc intake and hyperuricaemia.

- The multivariable model was adjusted for a considerable number of potentially confounding factors.

- This study adopted the food frequency questionnaire (FFQ), an effective measurement method for dietary micronutrient intake, which estimated annual dietary intake.

- The FFQ, when compared with blood concentration measurement, is a relatively less accurate method for instantly reflecting the level of micronutrients.

metabolism, exceeds the normal level. Previous studies have demonstrated close associations between HU and increased risks of gout as well as other medical problems such as type 2 diabetes, metabolic syndrome and cardiovascular disease. ${ }^{1-4}$ Over the past several decades, the prevalence of $\mathrm{HU}$ has increased worldwide. ${ }^{5}$ In recent epidemiological studies, the reported prevalence of HU ranged from $8.9 \%$ to $24.4 \%$ in different populations. ${ }^{6-8}$ Therefore, HU has emerged as a major health problem and is currently gaining more attention. ${ }^{6}$ However, the pathophysiology of $\mathrm{HU}$ has not been fully understood. ${ }^{9}$

Zinc $(\mathrm{Zn})$ is an essential trace element that plays a wide range of biological roles in catalytic, structural and regulatory functions. ${ }^{10}$ Acting as an antioxidant and antiinflammatory agent in humans, Zn may be associated with the level of serum uric acid, which may function as a pro-oxidant and proinflammatory factor under certain circumstances. ${ }^{11} 12$ Umeki et $a l^{13}$ revealed that oral $\mathrm{Zn}$ administration could normalise serum uric acid in a patient with Wilson's 
disease by improving liver dysfunction. In several animal studies, Zn supplementation or administration of $\mathrm{Zn}$ complex also showed normalisation of elevated serum uric acid levels in rats with aspirin-related damage, experimental diabetes or intestinal injury. ${ }^{14-16}$ Besides, a longitudinal study by Navarro-Alarcon et $a l^{17}$ found that uric acid was negatively linearly related to serum $\mathrm{Zn}$ in haemodialysis patients. In view of these factors, Zn deficiency may be related to $\mathrm{HU}$ to a certain extent. However, it should be noted that an animal study conducted by Bruno et $a l^{18}$ observed that plasma uric acid concentrations were significantly decreased among rats with zinc deficiency and a vitro study conducted by Bataille $e t a l^{19}$ demonstrated that zinc-induced cellular stress could decrease avian renal proximal tubule uric acid secretion and may therefore increase plasma uric acid concentration. Therefore, the effect of $\mathrm{Zn}$ on serum uric acid level still remains controversial. To the best of our knowledge, there has been no study conducted directly examining the association between dietary $\mathrm{Zn}$ intake and the prevalence of HU. The purpose of this cross-sectional study was to explore the aforementioned association based on the following hypothesis: dietary $\mathrm{Zn}$ intake is negatively associated with the prevalence of $\mathrm{HU}$.

\section{MATERIALS AND METHODS \\ Study population}

This cross-sectional study was conducted in the Department of Health Examination Center, Xiangya Hospital, Central South University, in Changsha, Hunan Province, China. We obtained approval for this study from the ethics committee at Xiangya Hospital, Central South University. We also obtained written informed consent from the participants in our study. The study design has been published previously. ${ }^{20}$ Routine health check-ups are very common in China, because the Chinese government encourages people to take periodic medical examinations. Registered nurses interviewed all participants during the examination, using a standard questionnaire, with the purpose of collecting information on demographic characteristics and health-related habits. Participants were selected according to the following inclusion criteria: (1) they were aged 40 years or above; (2) they were undergoing serum uric acid measurement; (3) they had completed the semiquantitative food frequency questionnaire (FFQ) on the average consumption of foods and drinks over the past 1 year; and (4) all the participant's basic characteristics, including age, gender, body mass index (BMI), smoking status, alcohol drinking status, etc, were available. In the beginning, this cross-sectional study included 10387 participants who were undergoing routine check-ups, including serum uric acid measurement, at the Department of Health Examination Center, Xiangya Hospital, Central South University, in Changsha, Hunan Province, China, from October 2013 to July 2014. At the time, 9420 individuals were aged over 40 years, and 9402 had basic characteristics, such as BMI, available. Eventually, 5168 participants completed the FFQ and the overall response rate of the survey was $54.9 \%$. There was no significant difference between participants who completed and those who did not complete the FFQ in terms of the prevalence of HU $(p=0.21)$ and in terms of characteristics, including age $(\mathrm{p}=0.12)$ and BMI $(\mathrm{p}=0.19)$.

\section{Assessment of HU}

All blood samples were drawn after a $12 \mathrm{~h}$ overnight fast and were kept at $4^{\circ} \mathrm{C}$ until analysis. Uric acid was detected on a Beckman Coulter AU 5800 system (Beckman Coulter Inc, Brea, California, USA). HU was defined by uric acid $\geq 416 \mu \mathrm{mol} / \mathrm{L}$ in males and $\geq 360 \mu \mathrm{mol} / \mathrm{L}$ in females.

\section{Assessment of dietary and non-dietary exposures}

Dietary intake was evaluated using a semi-quantitative food frequency questionnaire (SFFQ) that was specially designed for the population in Hunan province of China. It has been used and validated in several previously published studies. ${ }^{21} 22$ This SFFQ contained 63 food items that are regularly consumed in Hunan province. Participants were requested to answer how frequently (never, once per month, two to three times per month, one to three times per week, four to five times per week, once per day, twice per day, or three times and above per day) they consumed each food item in the past year. There were six options for the average amount of food consumed on each occasion: less than $100,100-200,201-300,301-400,401-500$, and over $500 \mathrm{~g}$. Colour pictures showing food samples with labelled weights were given to participants as a reference. The SFFQ was either self-administered or completed through interviews by professional researchers. The validity of the SFFQ was tested through comparing with the $24 \mathrm{~h}$ dietary recall method in 91 participants, where the tested samples were randomly selected from the same study population. The correlation coefficient between the SFFQ and the $24 \mathrm{~h}$ recall was 0.34 for the measurement of zinc intake. The strength of the correlation coefficient was also close to other similar published studies. ${ }^{23-25}$ The Chinese Food Composition Table was referenced to calculate the individual composition of macronutrients and micronutrients of the included foods. ${ }^{26}$ This SFFQ has been validated and used in a previously published study. ${ }^{27}$

The weight and height of each participant were respectively measured to calculate the BMI. Participants were also asked about their average frequency of physical activity (never, one to two times per week, three to four times per week, five times and above per week) and average duration of physical activity (less than half an hour, half an hour to $1,1-2$, more than $2 \mathrm{~h}$ ). Smoking and alcohol drinking status was asked about face to face. Blood fasting glucose, high density lipoprotein cholesterol (HDL-cholesterol), low density lipoprotein 
cholesterol (LDL-cholesterol) and triglyceride (TG), were also detected on the Beckman Coulter AU 5800 system (Beckman Coulter Inc, Brea, California, USA). Blood pressure was measured using an electronic sphygmomanometer. Participants with fasting glucose of $\geq 7.0 \mathrm{mmol} / \mathrm{L}$ or currently undergoing drug treatment for blood glucose control were regarded as diabetes patients, and participants with systolic blood pressure of $\geq 140 \mathrm{~mm} \mathrm{Hg}$ or diastolic blood pressure of $\geq 90 \mathrm{~mm} \mathrm{Hg}$, or currently using antihypertensive medication, were regarded as hypertension patients.

\section{Statistical analysis}

The continuous data are expressed as mean $\pm \mathrm{SD}$ (normally distributed data) or median and IQR (skewed distributed data), and the category data are expressed in percentage. $\mathrm{Zn}$ intake was classified into five categories based on the quintile distribution: $\leq 16.23,16.24-19.07$, $19.08-21.95,21.96-22.55$ and $\geq 22.56 \mathrm{mg} /$ day in males; and $\leq 13.63$, 13.64-15.98, 15.99-18.53, 18.54-21.99 and $\geq 22.00 \mathrm{mg} /$ day in females. The ORs with $95 \%$ CIs for the association between $\mathrm{HU}$ and dietary $\mathrm{Zn}$ were calculated for each quintile of $\mathrm{Zn}$ intake, respectively, and the quintile with the lowest value was regarded as the reference category. In order to calculate the adjusted OR values of each quintile of $\mathrm{Zn}$ intake, a minimally adjusted model and a multivariable adjusted model were adopted in the logistic analyses for males and females, respectively. Covariant variables in the minimally adjusted model included age, BMI and total energy intake. Covariant variables in the multivariable model included age, BMI, educational level, activity level, total energy intake, fibre intake, vitamin $\mathrm{C}$ intake, vitamin $\mathrm{E}$ intake, smoking status, alcohol drinking status, nutrient supplementation, diabetes, hypertension, HDL-cholesterol, LDLcholesterol and TG. Covariates were chosen based on some published studies. ${ }^{28-31}$ The female subgroup was also adjusted for menopausal status. Tests for linear trends were conducted based on logistic regression, using a median variable of $\mathrm{Zn}$ level in each category. Model fitness was assessed by a $\chi^{2}$ test and using a maximum likelihood method $(\mathrm{p}=0.000)$. We also examined the multicollinearity among the covariates by correlation coefficient matrix, no significant multicollinearity $(r>0.8)$ existed. Sensitivity analysis was conducted by excluding participants who had mineral (except calcium) supplementation. We also conducted a subgroup analysis by stratifying the data of participants with or without hypertension or diabetes. All data analyses were performed using SPSS V.17.0; a $p$ value equal to or less than 0.05 was considered to be statistically significant.

\section{RESULTS}

The basic characteristics of the study population in men and women are listed in table 1. A total of 5168 participants (2697 men and 2471 women) were included in the present study. The overall prevalence of HU among the participants of this cross-sectional study (aged 40 85 years, average age $=50.1 \pm 7.6$ ) was $16.7 \%$. Significant differences between males and females were observed for the prevalence of $\mathrm{HU}$, age, BMI, smoking status, alcohol drinking status, energy intake, fibre intake, vitamin intake, nutrient supplementation, education level, diabetes, hypertension, HDL-cholesterol and TG.

Table 2 presents the associations between $\mathrm{HU}$ and dietary $\mathrm{Zn}$ intake in males and females. For males, the prevalence of $\mathrm{HU}$ was $22.9 \%$ in this study. The unadjusted ORs suggested that no significant association existed between $\mathrm{Zn}$ intake and HU. However, after adjusting for age, BMI and energy intake, the results suggested a strong inverse association between $\mathrm{Zn}$ intake and HU. The ORs were 0.68 (95\% CI 0.45 to 0.92 ) in the second quintile, 0.63 (95\% CI 0.45 to 0.89 ) in the third quintile, 0.68 (95\% CI 0.46 to 1.00 ) in the fourth quintile and 0.55 (95\% CI 0.35 to 0.87 ) in the fifth quintile comparing the lowest quintile of $\mathrm{Zn}$ intake, respectively ( $\mathrm{p}$ for trend $=0.03$ ). In the multivariable adjusted model, the relative odds of $\mathrm{HU}$ were significantly decreased by 0.71 times in the second quintile of $\mathrm{Zn}$ intake (OR $0.71,95 \%$ CI 0.52 to $0.98, \mathrm{p}=0.039$ ), 0.65 times in the third quintile (OR $0.65,95 \%$ CI 0.44 to $0.94, \mathrm{p}=0.023$ ) and 0.56 times in the fifth quintile (OR $0.56,95 \%$ CI 0.32 to $0.97, \mathrm{p}=0.038$ ) compared with those in the lowest quintile, and $\mathrm{p}$ for trend was 0.064 . For females, the prevalence of $\mathrm{HU}$ was $10.0 \%$ in this study. Unadjusted, minimally adjusted and multivariable adjusted ORs all suggested that no significant association was observed between dietary zinc intake and HU. The multivariable-adjusted ORs $(95 \% \mathrm{CI})$ of $\mathrm{HU}$ across the five quintiles of $\mathrm{Zn}$ intake were 1.70 (95\% CI 1.07 to 2.71), 1.19 (95\% CI 0.67 to 2.11 ), 1.05 (95\% CI 0.52 to 2.11 ) and 1.38 (95\% CI 0.59 to 3.25 ) respectively, while $\mathrm{p}$ for trend was 0.582. After excluding participants with mineral (except calcium) supplementation, the outcomes did not change significantly in males and females.

The results of subgroup analysis are listed in table 3. In males without hypertension or diabetes, the inverse association between $\mathrm{Zn}$ intake and HU still existed ( $\mathrm{p}$ for trend $=0.03$ ). But there was no association between $\mathrm{Zn}$ intake and $\mathrm{HU}$ in males with hypertension or diabetes ( $p$ for trend $=0.57$ ). The outcomes suggest that the existence of hypertension or diabetes may weaken the association between $\mathrm{Zn}$ intake and HU. Outcomes from both female subgroups showed that there were no significant associations between $\mathrm{Zn}$ intake and $\mathrm{HU}$.

\section{DISCUSSION}

This cross-sectional study revealed that $\mathrm{Zn}$ intake was inversely associated with the prevalence of $\mathrm{HU}$ in male participants. The association was significant after considering the influence of age, BMI and energy intake, and, after that, minimum adjustment remained independent of further confounding factors such as vitamin $\mathrm{C}$ intake, alcohol drinking status and nutrient supplementation. 
Table 1 Characteristics among 5168 participants in the male and female population

\begin{tabular}{|c|c|c|c|}
\hline Characteristics & Male population $(n=2697)$ & Female population $(n=2471)$ & p Value \\
\hline Median Zn intake (mg/d) & 20.54 & 17.20 & \\
\hline Hyperuricaemia (\%) & 22.9 & 10.0 & 0.00 \\
\hline Age (years) & $52.71 \pm 7.48,51.04(47.12-57.70)$ & $53.49 \pm 7.66,51.70(47.85-58.70)$ & 0.00 \\
\hline Age range (years) & $40-85$ & $40-84$ & \\
\hline BMl $\left(\mathrm{kg} / \mathrm{m}^{2}\right)$ & $25.12 \pm 3.12,25.09(23.05-27.13)$ & $23.77 \pm 3.09,23.64(21.65-25.61)$ & 0.00 \\
\hline Smoking (\%) & 40.7 & 2.5 & 0.00 \\
\hline Alcohol drinking (\%) & 54.8 & 14.9 & 0.00 \\
\hline Activity level (h/w) & $2.18 \pm 3.50,0(0-4.5)$ & $2.38 \pm 3.58,0(0-4.5)$ & 0.20 \\
\hline $\begin{array}{l}\text { Mean total energy intake } \\
\text { (kcal/day) }\end{array}$ & $\begin{array}{l}1814.78 \pm 827.38,1689.96(1325.94- \\
2093.06)\end{array}$ & $\begin{array}{l}1468.61 \pm 683.40,1358.03(1057.54- \\
1722.57)\end{array}$ & 0.00 \\
\hline Mean fibre intake (g/day) & $20.14 \pm 14.94,16.68(9.99-29.00)$ & $16.48 \pm 12.89,12.65(7.58-21.84)$ & 0.00 \\
\hline Mean vitamin C intake (mg/day) & $116.42 \pm 72.38,108.84(72.38-143.31)$ & $119.50 \pm 75.41,109.37(71.73-144.36))$ & 0.55 \\
\hline Mean vitamin E intake (mg/day) & $30.91 \pm 14.06,28.61(21.58-37.25)$ & $28.44 \pm 14.63,25.34(19.21-34.67)$ & 0.00 \\
\hline Nutrient supplementation (\%) & 27.1 & 43.5 & 0.00 \\
\hline Calcium & 20.3 & 35.3 & 0.00 \\
\hline Vitamins & 9.0 & 15.0 & 0.00 \\
\hline Minerals (except calcium) & 0.7 & 0.8 & 0.66 \\
\hline $\begin{array}{l}\text { High school background or } \\
\text { above (\%) }\end{array}$ & 55.2 & 38.2 & 0.00 \\
\hline Diabetes (\%) & 11.9 & 7.3 & 0.00 \\
\hline Hypertension (\%) & 35.4 & 30.3 & 0.00 \\
\hline HDL-cholesterol (mg/dL) & $1.41 \pm 0.35,1.36(1.17-1.59)$ & $1.64 \pm 0.38,1.60(1.36-1.88)$ & 0.00 \\
\hline LDL-cholesterol (mg/dL) & $2.94 \pm 0.92,2.91(2.34-3.51)$ & $2.99 \pm 0.932 .95(2.37-3.56)$ & 0.17 \\
\hline Triglyceride (mg/dL) & $2.17 \pm 2.06,1.62(1.11-2.40)$ & $1.58 \pm 1.34,1.25(0.91-1.84)$ & 0.00 \\
\hline
\end{tabular}

Continuous data are showed as mean \pm SD and median (IQR), category data are shown as percentage.

BMI, body mass index; HDL, high-density lipoprotein; LDL, low density lipoprotein; Zn, zinc.

Besides, the inverse association noted between Zn intake and HU was only observed in males without hypertension or diabetes but not in those suffering from these two diseases. In females, however, no significant association was observed between dietary zinc intake and HU.

High prevalence of $\mathrm{HU}$ in the Chinese population may be related to recent dietary changes. ${ }^{32}$ Previous published data have shown that an increased intake of meat and seafood, or alcohol consumption, significantly increased the risk of developing HU. ${ }^{33}{ }^{34}$ On the other hand, randomised controlled trials revealed that some dietary interventions, such as dairy intake and vitamin C supplementation, might be protective against the development of HU. ${ }^{35}{ }^{36}$ Therefore, dietary modification is often recommended for patients with HU.

The findings of this cross-sectional study demonstrated that $\mathrm{Zn}$ intake was inversely associated with the prevalence of $\mathrm{HU}$ in males, indicating a potentially beneficial role of $\mathrm{Zn}$ intake in the development of $\mathrm{HU}$ in males. Because of its relatively high concentration compared with other antioxidants and its ability to scavenge oxygen radicals, uric acid is often, at physiological concentrations, considered a major hydrophilic antioxidant in human plasma. ${ }^{37} 38$ One of the main sites where the antioxidant property of uric acid has been demonstrated is the central nervous system, as neurons are remarkably susceptible to oxidative damage ${ }^{39}$ Previous studies focusing on neurological disease such as multiple sclerosis, Parkinson's disease and ischaemic stroke have suggested some potential protective role in raising serum uric acid. ${ }^{40-42}$ However, some studies have reported that HU was associated with an increased risk of some diseases related to oxidative stress, such as metabolic syndrome, cardiovascular disease and obesity. ${ }^{3} 4{ }^{4} 43$ The possible explanation may be that uric acid could stimulate oxidative stress through the renin-angiotensin system (RAS) in vascular endothelial cells as well as vascular smooth muscle cells, and increase nicotinamide adenine dinucleotide phosphate oxidase-derived reactive oxygen species production. ${ }^{4-46}$ Taken together, these findings provide evidence that uric acid may function as a pro-oxidant in $\mathrm{HU}$, despite its antioxidant properties under physiological conditions. ${ }^{47}$ The fact that $\mathrm{Zn}$, the most abundant trace intracellular element, has the ability to retard the oxidative process, has been recognised for many years. ${ }^{48}$ Based on the above analysis, the potentially beneficial role of dietary $\mathrm{Zn}$ intake to attenuate the development of $\mathrm{HU}$ in males may be related to the antioxidant properties of $\mathrm{Zn}$.

In the present study, age, BMI and total energy intake were correlated with dietary Zn intake and HU. When these important confounding factors were taken into consideration, a strong inverse association between $\mathrm{Zn}$ intake and $\mathrm{HU}$ was observed. In the study by Zhu et $a l^{7}$ increasing age and increasing BMI were associated with increased risk of HU. However, the mechanism of how these factors influenced the association between dietary $\mathrm{Zn}$ intake and HU is still unknown, and further studies 
Table 2 Relations between dietary $\mathrm{Zn}$ intake and hyperuricaemia $(\mathrm{n}=5168)$

\begin{tabular}{|c|c|c|c|c|c|c|}
\hline & \multicolumn{5}{|c|}{ Quintiles of $\mathrm{Zn}$ intake } & \multirow[b]{2}{*}{$\mathrm{p}$ for trend } \\
\hline & 1 (lowest) & 2 & 3 & 4 & 5 (highest) & \\
\hline \multicolumn{7}{|l|}{ Males $(n=2697)$} \\
\hline Median Zn intake (mg/d) & 14.06 & 17.68 & 20.54 & 23.51 & 28.42 & - \\
\hline Participants $(n)$ & 539 & 540 & 539 & 540 & 539 & - \\
\hline Unadjusted ORs & 1.00 (Reference) & 0.85 (0.64 to 1.13$)$ & $0.86(0.65$ to 1.15$)$ & $1.06(0.80$ to 1.40$)$ & 1.00 (0.76 to 1.32$)$ & 0.527 \\
\hline Minimally adjusted ORs* & 1.00 (Reference) & $0.68(0.45$ to 0.92$)$ & $0.63(0.45$ to 0.89$)$ & $0.68(0.46$ to 1.00$)$ & 0.55 (0.35 to 0.87$)$ & 0.030 \\
\hline Multivariable adjusted ORs† & 1.00 (Reference) & $0.71(0.52$ to 0.98$)$ & 0.65 (0.44 to 0.94$)$ & $0.71(0.45$ to 1.11$)$ & $0.56(0.32$ to 0.97$)$ & 0.064 \\
\hline \multicolumn{7}{|l|}{ Females $(n=2471)$} \\
\hline Median Zn intake (mg/day) & 11.82 & 14.91 & 17.21 & 20.00 & 24.97 & - \\
\hline Participants (n) & 494 & 494 & 496 & 494 & 493 & - \\
\hline Unadjusted ORs & 1.00 (Reference) & 1.52 (1.00 to 2.30$)$ & 1.07 (0.69 to 1.67$)$ & 1.03 (0.66 to 1.60$)$ & 1.38 (0.91 to 2.10$)$ & 0.478 \\
\hline Minimally adjusted ORs & 1.00 (Reference) & 1.61 (1.04 to 2.50$)$ & 1.19 (0.70 to 2.02$)$ & 1.13 (0.59 to 2.13$)$ & $1.53(0.71$ to 3.31$)$ & 0.356 \\
\hline Multivariable adjusted ORs $†$ & 1.00 (Reference) & 1.70 (1.07 to 2.71$)$ & 1.19 (0.67 to 2.11$)$ & $1.05(0.52$ to 2.11$)$ & $1.38(0.59$ to 3.25$)$ & 0.582 \\
\hline
\end{tabular}

Data are adjusted ORs (95\% Cls), unless otherwise indicated.

*Minimally adjusted model was adjusted for age, BMl and total energy intake.

tMultivariable adjusted model was adjusted for age, BMI, educational level, activity level, total energy intake, fibre intake, vitamin $\mathrm{C}$ intake, vitamin $\mathrm{E}$ intake, smoking status, alcohol drinking

status, nutrient supplementation, diabetes, hypertension, HDL-cholesterol, LDL-cholesterol and triglyceride. The female subgroup was also adjusted for menopausal status.

$\mathrm{BMI}$, body mass index; $\mathrm{HU}$, hyperuricaemia; $n$, number; $\mathrm{Zn}$, zinc.

Table 3 Subgroup analysis by stratifying the data of participants with or without hypertension or diabetes

\begin{tabular}{|c|c|c|c|c|c|c|}
\hline & \multicolumn{5}{|c|}{ Quintiles of Zn intake } & \multirow[b]{2}{*}{$p$ for trend } \\
\hline & 1 (lowest) & 2 & 3 & 4 & 5 (highest) & \\
\hline \multicolumn{7}{|c|}{ Males without hypertension or diabetes $(n=1587)$} \\
\hline Multivariable adjusted $\mathrm{ORs}^{*}$ & 1.00 (Reference) & $0.68(0.45$ to 1.05$)$ & $0.52(0.31$ to 0.86$)$ & $0.48(0.26$ to 0.90$)$ & 0.41 (0.19 to 0.90$)$ & 0.030 \\
\hline \multicolumn{7}{|c|}{ Males with hypertension or diabetes $(n=1110)$} \\
\hline Multivariable adjusted ORs* & 1.00 (Reference) & 0.69 (0.42 to 1.12$)$ & $0.79(0.45$ to 1.39$)$ & $1.02(0.53$ to 1.97$)$ & $0.72(0.32$ to 1.63$)$ & 0.572 \\
\hline \multicolumn{7}{|c|}{ Females without hypertension or diabetes $(n=1645)$} \\
\hline Multivariable adjusted $\mathrm{ORs}^{*}$ & 1.00 (Reference) & 1.49 (0.73 to 3.02$)$ & $1.21(0.52$ to 2.82$)$ & 0.91 (0.32 to 2.57$)$ & $1.20(0.34$ to 4.17$)$ & 0.847 \\
\hline \multicolumn{7}{|c|}{ Females with hypertension or diabetes $(n=826)$} \\
\hline Multivariable adjusted ORs* & 1.00 (Reference) & 1.79 (0.97 to 3.32$)$ & $1.14(0.53$ to 2.48$)$ & 1.07 (0.42 to 2.73$)$ & $1.43(0.44$ to 4.66$)$ & 0.671 \\
\hline
\end{tabular}


are needed to explore it. When a subgroup analysis stratified by males with hypertension or diabetes was performed, only those without hypertension or diabetes showed an inverse association between dietary Zn intake and HU. Several studies have showed that hypertension may be an independent risk factors for HU. ${ }^{732}$ Similarly, A recent review by Li $e t a t^{49}$ concluded that insulin resistance and HU shared a bidirectional causal effect. This collection of evidence may provide an explanation for how these two diseases could attenuate the inverse association between dietary $\mathrm{Zn}$ intake and $\mathrm{HU}$.

An interesting finding of this study is that the inverse effect of dietary $\mathrm{Zn}$ intake on $\mathrm{HU}$ is only valid for males, and not for females. One hypothesis is that the fractional zinc absorption in men is relatively greater compared to that in women. It has been proposed that men are more easily affected by $\mathrm{Zn}$ deficiency, a public health problem with an estimated prevalence of $17.3 \%$ among the world's population. ${ }^{50-52}$ Furthermore, Zn deficiency, as reported by previous studies, is associated with increased fractional $\mathrm{Zn}$ absorption. ${ }^{53}$ Taken together, fractional $\mathrm{Zn}$ absorption in men may be higher than in women, and therefore contribute to its protective effects against $\mathrm{HU}$ in men. Another potential explanation for the difference in effect by gender is that the high prevalence of zinc deficiency in males may make them more susceptible to the consequences of zinc deficiency. However, the current study did not confirm these speculations and further studies are needed to clarify the gender difference.

The present study has several strengths. First, this is the only study, to date, conducted on a large sample (5168 participants), to explore the association between dietary $\mathrm{Zn}$ intake and HU. Second, the multivariable model was adjusted for a considerable number of potentially confounding factors, such as diabetes, hypertension and blood lipid levels, which greatly improved the reliability of the results. Third, this study adopted FFQ an effective measurement method for dietary micronutrient intake, ${ }^{27} 5455$ which could estimate annual dietary intake. It might represent the average level of micronutrients more effectively than the measurement of instant serum level can.

Limitations of the present study should also be acknowledged. First, as is well recognised, flesh foods are the major sources of purine as well as bioavailable dietary zinc, and uric acid is the end product of purine metabolism. Accordingly, the inverse association observed between dietary Zn intake and HU may be due to the indirect effect of purine intake. Unfortunately, the data of the present study were not available for calculating purine intake. Second, this study provided only cross-sectional data, which precluded causal correlations, and, thus, further prospective longitudinal studies and intervention trials should be undertaken to establish a causal association between dietary $\mathrm{Zn}$ intake and HU. Since no previous research investigated the association between dietary $\mathrm{Zn}$ intake and $\mathrm{HU}$, the value of this study should not be blotted out due to its cross-sectional nature. Third, another limitation lies in the FFQ method itself, which is a relatively less accurate method for instantly reflecting the level of micronutrients when compared with blood concentration measurement. However, blood level may not fully reflect nutritional status, ${ }^{56}$ and it is also difficult to reflect the accurate circulating level after a certain period of time. Finally, further studies are needed to explore the mechanism of this correlation.

\section{CONCLUSIONS}

The findings of this cross-sectional study indicated that dietary $\mathrm{Zn}$ intake was inversely associated with $\mathrm{HU}$ in middle-aged and older males, but not in females. The association was significant after considering the influence of age, BMI and energy intake, and after that, minimum adjustment remained independent of further confounding factors such as vitamin $\mathrm{C}$ intake, alcohol drinking status and nutrient supplementation. As the study is cross sectional, its ability to prove causation is limited. Hence further studies based on rigorous designs should be recommended.

Contributors G-hL, D-xX, Y-IX and CZ collected the data. G-hL wrote the manuscript. D-XX, Y-IX and CZ helped in writing the manuscript. D-XX and $Y$-IX conducted statistical analysis and revised the manuscript. JW, TY, HL Y-IW, S-gG and Y-sL reviewed the manuscript. All authors contributed to the design of the study.

Funding This work was supported by Hunan Provincial Innovation Foundation for Postgraduate (CX2014A005), the Fundamental Research Funds for the Central Universities of Central South University, the National Natural Science Foundation of China (Number 81201420, 81272034, 81472130), the Provincial Science Foundation of Hunan (Number 14JJ3032), the Scientific Research Project of the Development and Reform Commission of Hunan Province ((2013)1199), the Scientific Research Project of Science and Technology Office of Hunan Province (2013SK2018), and the Doctoral Scientific Fund Project of the Ministry of Education of China (20120162110036).

Competing interests None declared.

Patient consent Obtained.

Ethics approval The study was approved by the ethics committee at Xiangya Hospital, Central South University.

Provenance and peer review Not commissioned; externally peer reviewed.

Data sharing statement No additional data are available.

Open Access This is an Open Access article distributed in accordance with the Creative Commons Attribution Non Commercial (CC BY-NC 4.0) license, which permits others to distribute, remix, adapt, build upon this work noncommercially, and license their derivative works on different terms, provided the original work is properly cited and the use is non-commercial. See: http:// creativecommons.org/licenses/by-nc/4.0/

\section{REFERENCES}

1. Roddy E, Doherty M. Epidemiology of gout. Arthritis Res Ther 2010;12:223.

2. Sluijs I, Beulens JW, van der A DL, et al. Plasma uric acid is associated with increased risk of type 2 diabetes independent of diet and metabolic risk factors. J Nutr 2013;143:80-5.

3. Yoo TW, Sung KC, Shin HS, et al. Relationship between serum uric acid concentration and insulin resistance and metabolic syndrome. Circ J 2005;69:928-33. 
4. Okura T, Higaki J, Kurata M, et al. Elevated serum uric acid is an independent predictor for cardiovascular events in patients with severe coronary artery stenosis: subanalysis of the Japanese Coronary Artery Disease (JCAD) Study. Circ J 2009;73:885-91.

5. Edwards NL. The role of hyperuricemia in vascular disorders. Curr Opin Rheumatol 2009;21:132-7.

6. Liu $\mathrm{H}$, Zhang $\mathrm{XM}$, Wang $\mathrm{YL}$, et al. Prevalence of hyperuricemia among Chinese adults: a national cross-sectional survey using multistage, stratified sampling. J Nephrol 2014. Published Online First: 1 Apr 2014. doi:10.1007/s40620-014-0082-z

7. Zhu Y, Pandya BJ, Choi HK. Prevalence of gout and hyperuricemia in the US general population: the National Health and Nutrition Examination Survey 2007-2008. Arthritis Rheum 2011;63:3136-41.

8. Uaratanawong S, Suraamornkul S, Angkeaw S, et al. Prevalence of hyperuricemia in Bangkok population. Clin Rheumatol 2011;30:887-93.

9. Qiu L, Cheng XQ, Wu J, et al. Prevalence of hyperuricemia and its related risk factors in healthy adults from Northern and Northeastern Chinese provinces. BMC Public Health 2013;13:664.

10. Tuerk MJ, Fazel N. Zinc deficiency. Curr Opin Gastroenterol 2009;25:136-43.

11. Prasad AS. Zinc: an antioxidant and anti-inflammatory agent: role of zinc in degenerative disorders of aging. J Trace Elem Med Biol 2014;28:364-71.

12. Sautin $Y Y$, Johnson RJ. Uric acid: the oxidant-antioxidant paradox. Nucleosides Nucleotides Nucleic Acids 2008;27:608-19.

13. Umeki S, Ohga R, Konishi $\mathrm{Y}$, et al. Oral zinc therapy normalizes serum uric acid level in Wilson's disease patients. Am J Med Sci 1986;292:289-92.

14. Kesik V, Lenk MK, Kurekci AE, et al. Do zinc and selenium prevent the antioxidant, hepatic and renal system impairment caused by aspirin in rats? Biol Trace Elem Res 2008;123:168-78.

15. Vijayaraghavan K, Iyyam PS, Subramanian SP. Design, synthesis and characterization of zinc-3 hydroxy flavone, a novel zinc metallo complex for the treatment of experimental diabetes in rats. Eur $J$ Pharmacol 2012;680:122-9.

16. Arda-Pirincci P, Bilgin-Sokmen B, Yanardag R, et al. Effects of zinc on intestinal injury and some serum parameters in ethanol-administered rats. Biosci Biotechnol Biochem 2009;73:260-7.

17. Navarro-Alarcon M, Reyes-Perez A, Lopez-Garcia $\mathrm{H}$, et al. Longitudinal study of serum zinc and copper levels in hemodialysis patients and their relation to biochemical markers. Biol Trace Elem Res 2006;113:209-22.

18. Bruno RS, Song Y, Leonard SW, et al. Dietary zinc restriction in rats alters antioxidant status and increase plasma $F_{2}$ isoprostanes. $J$ Nutr Biochem 2007;18:509-18.

19. Bataille AM, Maffeo CL, Renfro JL. Avian renal proximal tubule urate secretion is inhibited by cellular stress-induced AMP-activated protein kinase. Am J Physiol Renal Physiol 2011;300:F1327-38.

20. Zhang $\mathrm{Y}$, Zeng $\mathrm{C}$, Li H, et al. Relationship between cigarette smoking and radiographic knee osteoarthritis in Chinese population: a cross-sectional study. Rheumatol Int 2015;35:1211-17.

21. Zeng $\mathrm{C}$, Li H, Wei J, et al. Association between dietary magnesium intake and radiographic knee osteoarthritis. PLOS ONE 2015;10: e0127666.

22. Wei J, Zeng C, Gong QY, et al. Associations between dietary antioxidant intake and metabolic syndrome. PLOS ONE 2015;10: e0130876.

23. Dehghan $\mathrm{M}$, del Cerro S, Zhang $\mathrm{X}$, et al. Validation of a semi-quantitative Food Frequency Questionnaire for Argentinean adults. PLOS ONE 2012;7:e37958.

24. Horwath CC. Validity of a short food frequency questionnaire for estimating nutrient intake in elderly people. Br J Nutr 1993;70:3-14.

25. Zhuang M, Yuan Z, Lin L, et al. Reproducibility and relative validity of a food frequency questionnaire developed for adults in Taizhou, China. PLOS ONE 2012;7:e48341.

26. Yang Y, ed. China food composition, the second edition. Peking University Medical Press, 2009.

27. Wei J, Zeng C, Gong QY, et al. The association between dietary selenium intake and diabetes: a cross-sectional study among middle-aged and older adults. Nutr J 2015;14:18

28. Bae J, Shin DH, Chun BY, et al. The effect of vitamin C intake on the risk of hyperuricemia and serum uric acid level in Korean Multi-Rural Communities Cohort. Joint Bone Spine 2014;81:513-19.

29. Ford ES, Choi HK. Associations between concentrations of uric acid with concentrations of vitamin A and beta-carotene among adults in the United States. Nutr Res 2013;33:995-1002.

30. Yadav D, Lee ES, Kim HM, et al. Prospective study of serum uric acid levels and incident metabolic syndrome in a Korean rural cohort. Atherosclerosis 2015;241:271-7.
31. Peng TC, Wang CC, Kao TW, et al. Relationship between hyperuricemia and lipid profiles in US Adults. Biomed Res Int 2015;2015:127596.

32. Miao Z, Li C, Chen Y, et al. Dietary and lifestyle changes associated with high prevalence of hyperuricemia and gout in the Shandong coastal cities of Eastern China. J Rheumatol 2008;35:1859-64.

33. Choi HK, Liu S, Curhan G. Intake of purine-rich foods, protein, and dairy products and relationship to serum levels of uric acid: the third national health and nutrition examination survey. Arthritis Rheum 2005;52:283-9.

34. Sugie T, Imatou T, Miyazaki M, et al. The effect of alcoholic beverage type on hyperuricemia in Japanese male office workers. $J$ Epidemiol 2005;15:41-7.

35. Huang HY, Appel LJ, Choi MJ, et al. The effects of vitamin C supplementation on serum concentrations of uric acid: results of a randomized controlled trial. Arthritis Rheum 2005;52:1843-7.

36. Dalbeth N, Wong S, Gamble GD, et al. Acute effect of milk on serum urate concentrations: a randomised controlled crossover trial. Ann Rheum Dis 2010;69:1677-82.

37. Ghiselli A, Serafini M, Natella F, et al. Total antioxidant capacity as a tool to assess redox status: critical view and experimental data. Free Radic Biol Med 2000;29:1106-14.

38. Sevanian A, Davies KJ, Hochstein P. Serum urate as an antioxidant for ascorbic acid. Am J Clin Nutr 1991;54:1129S-34S.

39. Bowman GL, Shannon J, Frei B, et al. Uric acid as a CNS antioxidant. J Alzheimers Dis 2010;19:1331-6.

40. Hooper DC, Spitsin S, Kean RB, et al. Uric acid, a natural scavenge of peroxynitrite, in experimental allergic encephalomyelitis and multiple sclerosis. Proc Natl Acad Sci USA 1998;95:675-80.

41. de Lau LM, Koudstaal PJ, Hofman A, et al. Serum uric acid levels and the risk of Parkinson disease. Ann Neurol 2005;58:797-800.

42. Amaro S, Urra X, Gomez-Choco M, et al. Uric acid levels are relevant in patients with stroke treated with thrombolysis. Stroke 2011;42:S28-32.

43. Ogura T, Matsuura K, Matsumoto $\mathrm{Y}$, et al. Recent trends of hyperuricemia and obesity in Japanese male adolescents, 1991 through 2002. Metabolism 2004;53:448-53.

44. Yu MA, Sanchez-Lozada LG, Johnson RJ, et al. Oxidative stress with an activation of the renin-angiotensin system in human vascular endothelial cells as a novel mechanism of uric acid-induced endothelial dysfunction. J Hypertens 2010;28:1234-42.

45. Corry DB, Eslami P, Yamamoto K, et al. Uric acid stimulates vascular smooth muscle cell proliferation and oxidative stress viathe vascular renin-angiotensin system. J Hypertens 2008;26:269-75.

46. Sautin YY, Nakagawa T, Zharikov S, et al. Adverse effects of the classic antioxidant uric acid in adipocytes: NADPH oxidasemediated oxidative/nitrosative stress. Am J Physiol Cell Physiol 2007;293: C584-96.

47. Kadowaki D, Sakaguchi S, Miyamoto $\mathrm{Y}$, et al. Direct radical scavenging activity of benzbromarone provides beneficial antioxidant properties for Hyperuricaemia treatment. Biol Pharm Bull 2015;18:487-92.

48. Powell SR. The antioxidant properties of zinc. J Nutr 2000;130:1447S-54S.

49. Li C, Hsieh MC, Chang SJ. Metabolic syndrome, diabetes, and hyperuricemia. Curr Opin Rheumatol 2013;25:210-16.

50. Kvamme JM, Grønli O, Jacobsen BK, et al. Risk of malnutrition and zinc deficiency in community-living elderly men and women: the Tromsø Study. Public Health Nutr 2015;18:1907-13.

51. Agte VV, Chiplonkar SA, Tarwadi KV. Factors influencing zinc status of apparently healthy Indians. J Am Coll Nutr 2005;24:334-41.

52. Wessells KR, Brown KH. Estimating the global prevalence of zinc deficiency: results based on zinc availability in national food supplies and the prevalence of stunting. PLOS ONE 2012;7:e50568.

53. Lee DY, Prasad AS, Hydrickadair C, et al. Homeostasis of zinc in marginal human zinc deficiency-role of absorption and endogenous excretion of zinc. J Lab Clin Med 1993;122:549-56.

54. Zeng C, Wei J, Lei GH. Food frequency questionnaire is an effective method for measuring micronutrient intake. Osteoarthritis Cartilage 2014;22:1947-8.

55. Tangney CC, Bienias JL, Evans DA, et al. Reasonable estimates of serum vitamin $E$, vitamin $C$, and beta-cryptoxanthin are obtained with a food frequency questionnaire in older black and white adults J Nutr 2004;134:927-34.

56. Fortmann SP, Burda BU, Senger CA, et al. Vitamin and mineral supplements in the primary prevention of cardiovascular disease and cancer: an updated systematic evidence review for the US Preventive Services Task Force. Ann Intern Med 2013;159:824-34. 